\title{
(C) OPEN ACCESS \\ Long work hours, weekend working and depressive symptoms in men and women: findings from a UK population-based study
}

\author{
Gillian Weston, ${ }^{1}$ Afshin Zilanawala, ${ }^{1,2}$ Elizabeth Webb, ${ }^{3}$ Livia A Carvalho, ${ }^{4}$ \\ Anne McMunn ${ }^{1}$
}

${ }^{1}$ Research Department of Epidemiology and Public Health, University College London, London, UK

${ }^{2}$ Human Development and Family Science, Oregon State University, Corvallis, Oregon, USA

${ }^{3}$ Department of Research and Policy, Age UK, London, UK

${ }^{4}$ Department of Clinical Pharmacology, William Harvey Research Institute, Queen Mary University of London, London, UK

Correspondence to Ms Gillian Weston, Research Department of Epidemiology and Public Health, University College, London WC1E 6BT, UK; gillian.weston.14@ucl.ac.uk

Received 9 July 2018 Revised 24 October 2018 Accepted 10 January 2019 Published Online First 25 February 2019

\section{ABSTRACT}

Background Globalised and 24/7 business operations have fuelled demands for people to work long hours and weekends. Research on the mental health effects of these intensive temporal work patterns is sparse, contradictory or has not considered gender differences. Our objective was to examine the relationship between these work patterns and depressive symptoms in a large nationally representative sample of working men and women in the UK.

Method The current study analysed data from Understanding Society, the UK Household Longitudinal Study, of 11215 men and 12188 women in employment or self-employment at the time of the study. Ordinary least squares regression models, adjusted for potential confounders and psychosocial work factors, were used to estimate depressive symptoms across categories of work hours and weekend work patterns.

Results Relative to a standard 35-40 hours/week, working 55 hours/week or more related to more depressive symptoms among women $(B=0.75,95 \% \mathrm{Cl}$ 0.12 to 1.39 ), but not for men $(B=0.24,95 \% \mathrm{Cl}-0.10$ to 0.58$)$. Compared with not working weekends, working most or all weekends related to more depressive symptoms for both men ( $B=0.34,95 \% \mathrm{Cl} 0.08$ to 0.61$)$ and women ( $B=0.50,95 \% \mathrm{Cl} 0.20$ to 0.79); however, working some weekends only related to more depressive symptoms for men ( $B=0.33,95 \% \mathrm{Cl} 0.11$ to 0.55$)$, not women ( $B=0.17,95 \% \mathrm{Cl}-0.09$ to 0.42 ).

Conclusion Increased depressive symptoms were independently linked to working extra-long hours for women, whereas increased depressive symptoms were associated with working weekends for both genders, suggesting these work patterns may contribute to worse mental health.

\section{INTRODUCTION}

The demands of operating a 24/7 globalised society is partially met by work patterns that elongate working hours and extend the working week. ${ }^{1}$ In eastern Asian countries the risk of karoshi (death due to overwork) has increased, ${ }^{2}{ }^{3}$ while across EU countries atypical work hours have become a feature for a significant proportion of people. ${ }^{4}$ In the UK, there are concerns about unregulated and frequently unpaid overtime, ${ }^{5}$ and work-related stress, often linked to workload, accounts for millions of lost working days every year. ${ }^{6}$ Despite this, other than studies on shift work, ${ }^{7}$ few epidemiological studies have considered the impact of temporal work patterns on mental health.

To our knowledge, although weekend working has been associated with poor work-life balance ${ }^{8}$ and work-family conflict, ${ }^{9} 10$ just four studies have examined its relationship to mental health. While three found evidence of job stress or psychological strain among weekend workers relative to weekday workers, ${ }^{11-13}$ in the fourth there was no association between working weekends and depressive symptoms. ${ }^{14}$ Long work hours has attracted more research attention. Recent reviews and a meta-analysis concluded there were some adverse effects of long hours on depressive mood, but these were often small, non-significant, or greater for women. ${ }^{15-17}$

Research has shown that gender plays a significant role in the way that work is organised, experienced and rewarded, not least in terms of occupational segregation, job status, mobility, and inequality in earnings, but also in work attitudes, behaviour and social relations. ${ }^{18}$ There are also suggestions that men and women perceive and respond differently to work demands such as the quantity of work and time-pressures. ${ }^{19}$ Despite this and recommendations that studies about work and health should address gender differences, ${ }^{20}$ most studies on temporal work patterns focus only on men or do not separate men and women in their analysis. Furthermore, although psychosocial work factors link to both working patterns and depression, few of the studies on temporal work patterns take them into account. ${ }^{21}$ Moreover, there is heterogeneity in the way that long hours are defined, ${ }^{22}$ with parttime workers sometimes categorised as the reference group despite part-time work being associated with health problems. ${ }^{23}$ A further limitation is that much of the existing research on UK workers relates to specific workplaces or occupations such as civil servants which, though informative, may not be representative of the general population of workers. $^{24}$

To facilitate generalisability, disaggregate by gender, adjust for a range of covariates including psychosocial work factors, and use the standard working week of 35-40 hours and weekday working as our reference categories, our aim was to investigate the linkages of temporal work patterns with mental health using workers' data from a large nationally representative sample of the UK population. Our hypothesis was that in comparison 


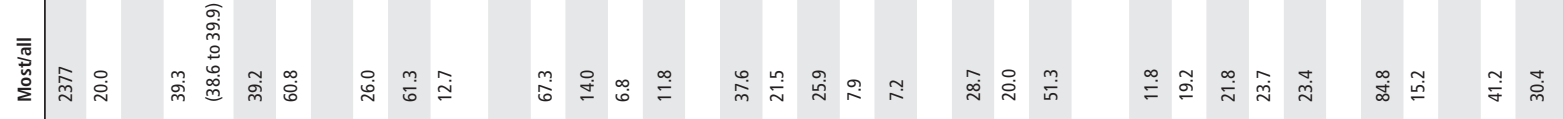

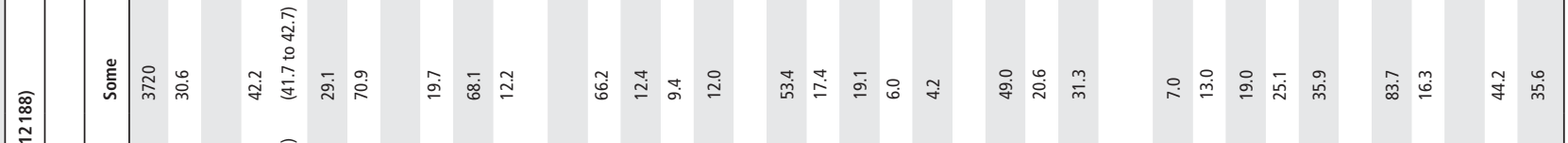

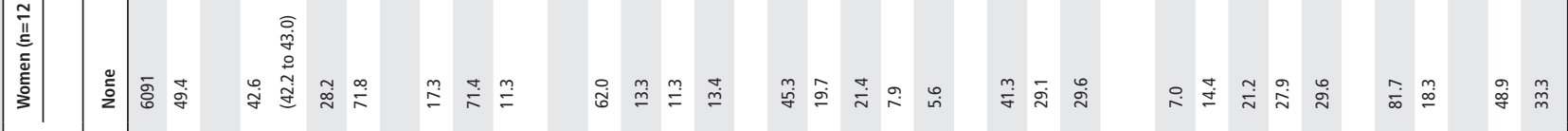

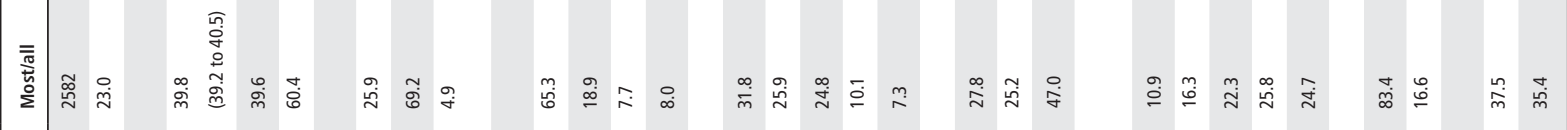

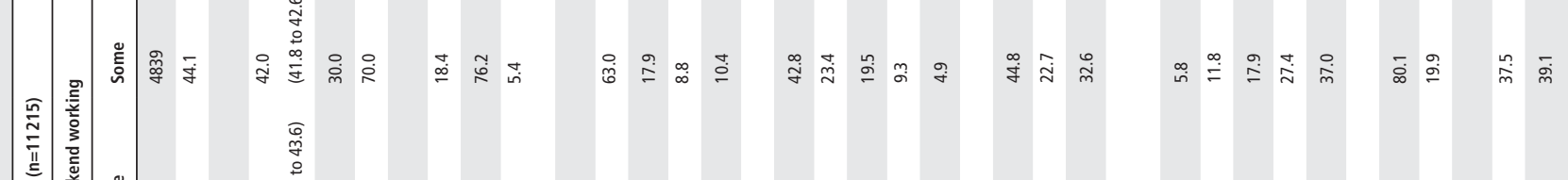

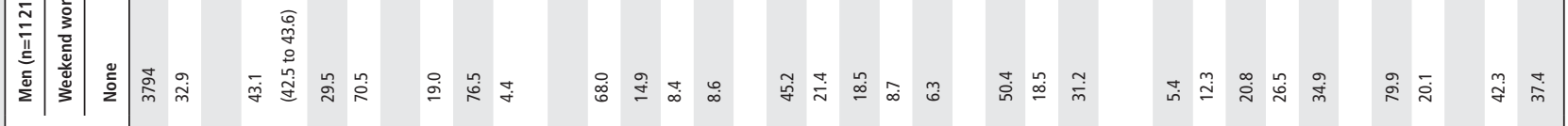

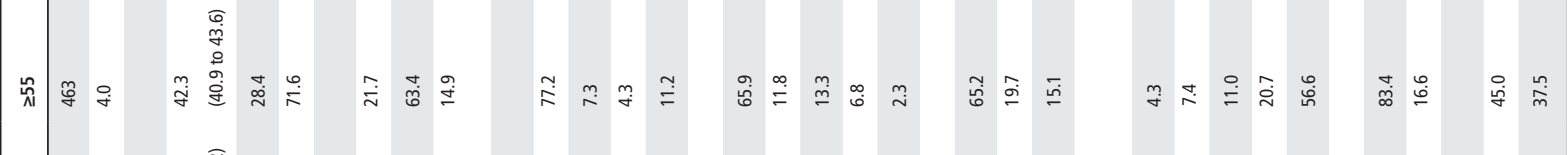

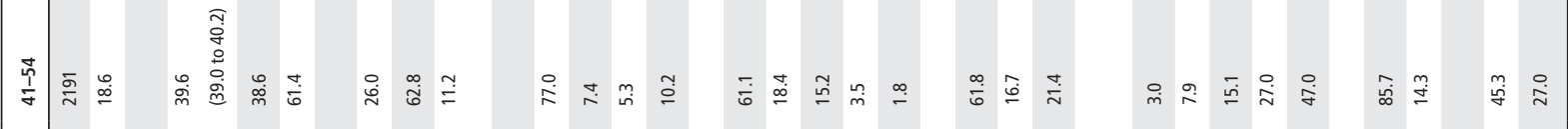

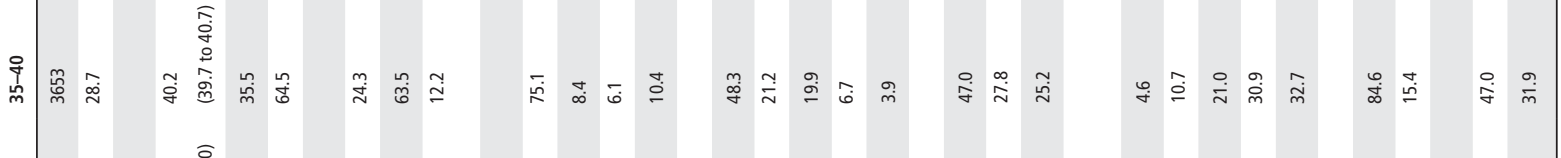

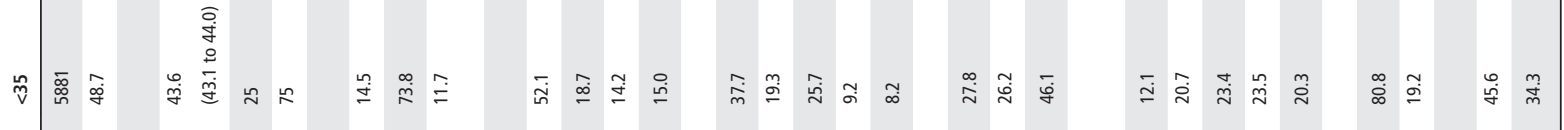

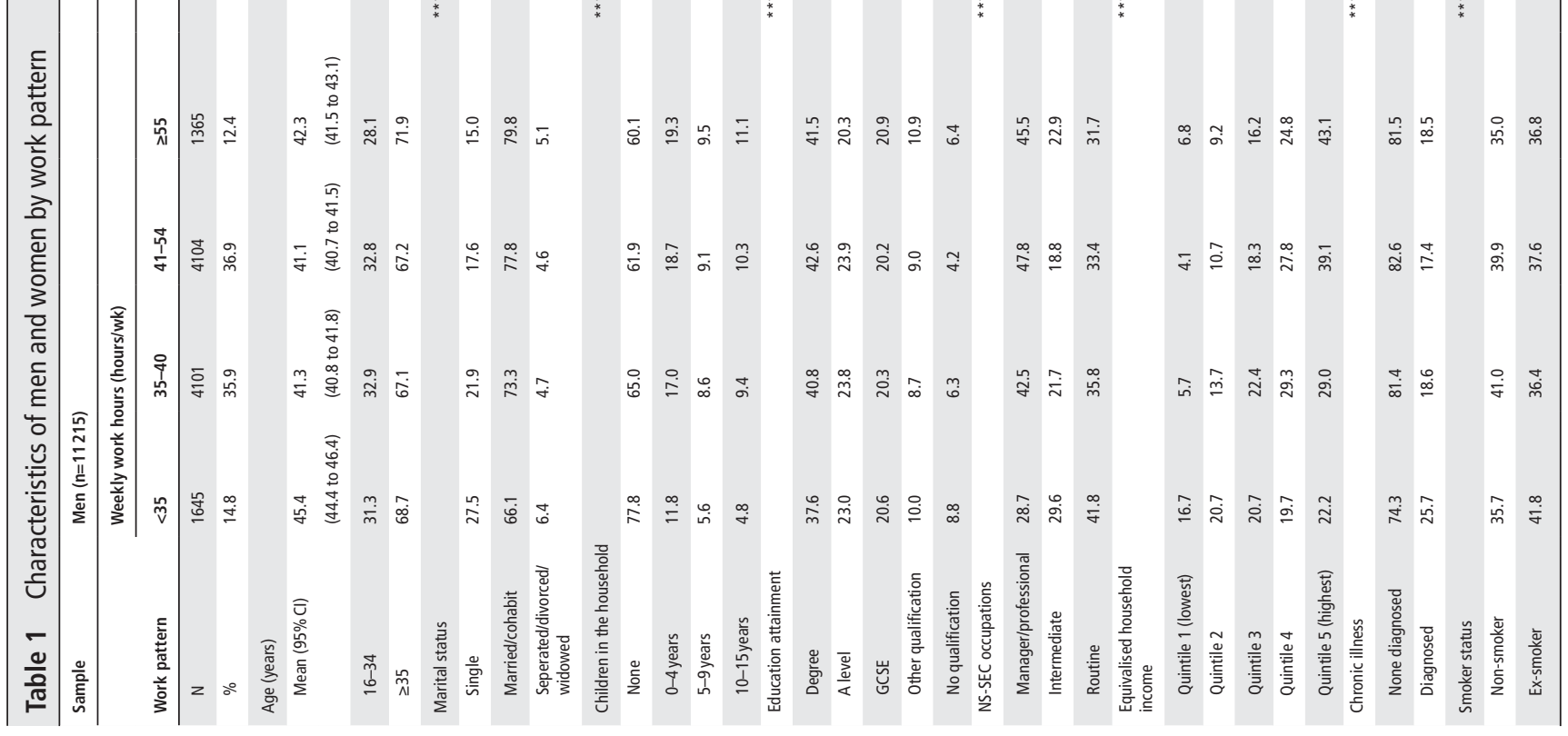




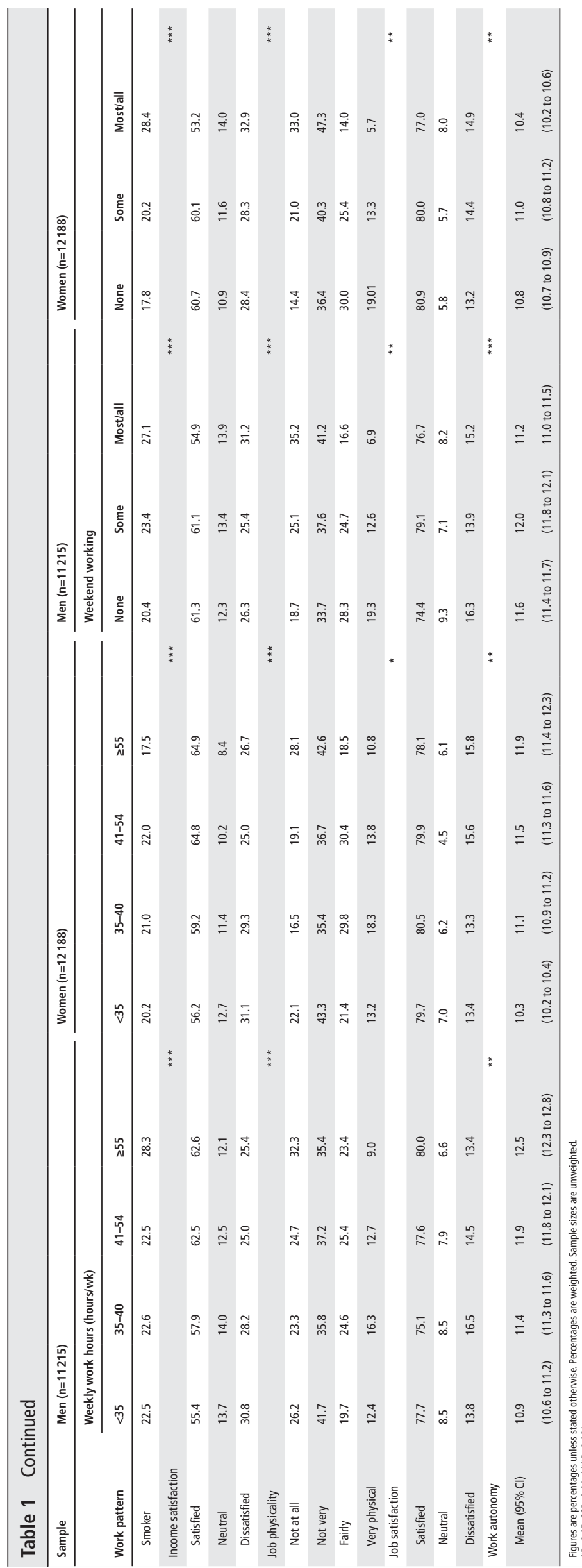


Table 2 Unadjusted mean depressive symptoms for work arrangements and covariates for men and women

\begin{tabular}{|c|c|c|}
\hline & Men & Women \\
\hline Temporal work patterns & $\begin{array}{l}\text { Mean GHQ-12 } \\
(95 \% \mathrm{Cl})\end{array}$ & $\begin{array}{l}\text { Mean GHQ-12 } \\
(95 \% \mathrm{Cl})\end{array}$ \\
\hline \multicolumn{3}{|l|}{ Weekly work hours (hours/week) } \\
\hline$<35$ & 10.1 (9.7 to 10.5$)$ & 11.1 (10.9 to 11.2$)$ \\
\hline $35-40 \dagger$ & 10.1 (9.9 to 10.3$)$ & 11.0 (10.8 to 11.2$)$ \\
\hline $41-54$ & $10.0(9.8$ to 10.2$)$ & $11.2(10.9$ to 11.5$)$ \\
\hline$\geq 55$ & 10.1 (9.8 to 10.4$)$ & $11.8(11.1 \text { to } 12.4)^{*}$ \\
\hline \multicolumn{3}{|l|}{ Weekend work } \\
\hline No weekendst & 9.9 (9.8 to 10.1$)$ & 10.9 (10.7 to 11.1$)$ \\
\hline Some weekends & 10.1 (10.0 to 10.3$)$ & 11.1 (10.9 to 11.3$)$ \\
\hline Most/all weekends & 10.1 (9.9 to 10.4$)$ & $11.5(11.2 \text { to } 11.8)^{* * *}$ \\
\hline \multicolumn{3}{|l|}{ Covariates } \\
\hline \multicolumn{3}{|l|}{ Age (years) } \\
\hline $16-34$ & $9.8(9.6 \text { to } 9.9)^{* * *}$ & $10.8(10.6 \text { to } 11.1)^{* *}$ \\
\hline$\geq 35 \dagger$ & $10.2(10.1$ to 10.3$)$ & $11.2(11.1$ to 11.3$)$ \\
\hline \multicolumn{3}{|l|}{ Marital status } \\
\hline Single & $9.8(9.5 \text { to } 10.0)^{*}$ & $11.0(10.7$ to 11.3$)$ \\
\hline Marriedt & 10.1 (10.0 to 10.2$)$ & $11.0(10.8$ to 11.1$)$ \\
\hline Separated/divorced/widowed & $10.5(10.0$ to 10.9$)$ & $11.9(11.5 \text { to } 12.2)^{* * *}$ \\
\hline \multicolumn{3}{|l|}{ Children in the household } \\
\hline Nonet & $10.0(9.8$ to 10.1$)$ & $11.0(10.8$ to 11.1$)$ \\
\hline Aged 0-4years & $10.0(9.8$ to 10.2$)$ & $11.2(10.9$ to 11.5$)$ \\
\hline Aged 5-9years & $10.4(10.1 \text { to } 10.8)^{*}$ & $11.0(10.7$ to 11.4$)$ \\
\hline Aged 10-15years & $10.6(10.3 \text { to } 11.0)^{* * *}$ & $11.5(11.2 \text { to } 11.8)^{* *}$ \\
\hline \multicolumn{3}{|l|}{ Educational attainment } \\
\hline Degree (or higher) $\dagger$ & $10.3(10.1$ to 10.4$)$ & $11.0(10.8$ to 11.1$)$ \\
\hline A levels (or equivalent) & $10.0(9.8$ to 10.3$)$ & $11.0(10.8$ to 11.3$)$ \\
\hline GCSEs (or equivalent) & $9.9(9.7 \text { to } 10.1)^{* *}$ & $11.3(11.1 \text { to } 11.6)^{*}$ \\
\hline Other qualification & $10.0(9.7$ to 10.3$)$ & $11.5(11.1 \text { to } 11.9)^{*}$ \\
\hline No qualifications & $9.7(9.3 \text { to } 10.2)^{*}$ & $10.8(10.3$ to 11.3$)$ \\
\hline \multicolumn{3}{|l|}{ NS-SEC occupations } \\
\hline Managerial/professional† & $10.2(10.0$ to 10.3$)$ & 11.1 (10.9 to 11.3$)$ \\
\hline Intermediate & $10.2(10.0$ to 10.5$)$ & 10.9 (10.7 to 11.2$)$ \\
\hline Routine & $9.9(9.7 \text { to } 10.0)^{* *}$ & $11.2(10.9$ to 11.4$)$ \\
\hline \multicolumn{3}{|l|}{ Equivalised household income } \\
\hline 1st quintile & $10.6(10.2 \text { to } 11.0)^{* *}$ & $11.7(11.4 \text { to } 12.2)^{* * *}$ \\
\hline 2nd quintile & $10.3(10.0 \text { to } 10.5)^{*}$ & $11.5(11.2 \text { to } 11.8)^{* * *}$ \\
\hline 3rd quintile & 10.1 (9.8 to 10.3$)$ & 10.9 (10.7 to 11.2$)$ \\
\hline 4th quintile & 10.1 (9.9 to 10.3$)$ & 11.0 (10.8 to 11.3$)$ \\
\hline 5th quintile (highest amount) $\dagger$ & $9.9(9.7$ to 10.1$)$ & $10.9(10.7$ to 11.1$)$ \\
\hline \multicolumn{3}{|l|}{ Chronic illness: } \\
\hline Not diagnosed $t$ & $10.0(9.8$ to 10.1$)$ & $11.0(10.8$ to 11.1$)$ \\
\hline Diagnosed & $10.5(10.3 \text { to } 10.8)^{* * *}$ & $11.7(11.4 \text { to } 12.0)^{* * *}$ \\
\hline \multicolumn{3}{|l|}{ Smoker status: } \\
\hline Non-smokert & $9.9(9.7$ to 10.0$)$ & $10.7(10.5$ to 10.9$)$ \\
\hline Ex-smoker & 10.0 (9.9 to 10.2$)$ & $11.1(10.9 \text { to } 11.3)^{* * *}$ \\
\hline Smoker & $10.5(10.2 \text { to } 10.7)^{* * *}$ & $11.9(11.6 \text { to } 12.2)^{* * *}$ \\
\hline \multicolumn{3}{|l|}{ Psychosocial work conditions } \\
\hline \multicolumn{3}{|l|}{ Satisfaction with income } \\
\hline Satisfiedt & 9.1 (9.0 to 9.3$)$ & $10.0(9.8$ to 10.1$)$ \\
\hline Neutral satisfaction & $10.2(9.9 \text { to } 10.5)^{* * *}$ & $11.5(11.2 \text { to } 11.9)^{* * *}$ \\
\hline
\end{tabular}

Continued
Table 2 Continued

\begin{tabular}{|c|c|c|}
\hline & Men & Women \\
\hline Temporal work patterns & $\begin{array}{l}\text { Mean GHQ-12 } \\
(95 \% \mathrm{Cl})\end{array}$ & $\begin{array}{l}\text { Mean GHQ-12 } \\
(95 \% \mathrm{Cl})\end{array}$ \\
\hline Dissatisfied & $12.0(11.8 \text { to } 12.3)^{* * *}$ & $13.1(12.9 \text { to } 13.4)^{* * *}$ \\
\hline \multicolumn{3}{|l|}{ Job physicality: } \\
\hline Not at all physicalt & 9.7 (9.5 to 9.9$)$ & 11.0 (10.7 to 11.3$)$ \\
\hline Not very physical & $10.0(9.8 \text { to } 10.2)^{*}$ & 11.0 (10.8 to 11.2$)$ \\
\hline Fairly physical & $10.4(10.1 \text { to } 10.6)^{* * *}$ & $11.1(10.8$ to 11.3$)$ \\
\hline Very physical & $10.5(10.2 \text { to } 10.8)^{* * *}$ & $11.4(11.1 \text { to } 11.7)^{*}$ \\
\hline \multicolumn{3}{|l|}{ Job satisfaction } \\
\hline Satisfiedt & 9.5 (9.3 to 9.6$)$ & 10.5 (10.3 to 10.6$)$ \\
\hline Neutral satisfaction & $11.2(10.8 \text { to } 11.5)^{* * *}$ & $12.7(12.2 \text { to } 13.2)^{* * *}$ \\
\hline Dissatisfied & $12.6(12.3 \text { to } 13.0)^{* * *}$ & $14.0(13.6 \text { to } 14.3)^{* * *}$ \\
\hline
\end{tabular}

† Denotes reference category. Means are weighted.

${ }^{*} \mathrm{P}<0.05 ;{ }^{* *} \mathrm{P}<0.01 ;{ }^{* * *} \mathrm{P}<0.001$.

GHQ-12, 12-item General Health Questionnaire; NS-SEC, National Statistics Socio-

Economic Classification.

to workers who work standard full-time weekly work hours or weekdays, those who do not will have an elevated risk of depression.

\section{METHODS}

\section{Sample}

Understanding Society, the UK Household Longitudinal Study (UKHLS) is a longitudinal study following people living in around 40000 households throughout the UK. It represents the diversity of participants of all ages, ethnicities, and employment status in all four constituent countries. We did not use the first wave of the UKHLS (2009 to 2011) because information on weekend working and work conditions was not available. For the second wave (wave 2, 2010 to 2012) 14797 men and 14437 women aged 16 and over were employed or self-employed and not in full-time education; of these 11215 men and 12188 women had data on the outcome. UKHLS data are publicly available and data collection was approved by the University of Essex ethics committee.

\section{Measures}

\section{Depressive symptoms}

Depressive symptoms were measured by the 12 -item General Health Questionnaire (GHQ-12), a psychometrically valid tool for studying psychological distress in general and clinical populations. ${ }^{25}$ At wave 2 this tool was administered to participants as part of a computer assisted self-completion questionnaire.

Each item of the GHQ-12 enquires about a specific symptom and whether the participant's mood state differs from their normal state by asking them to select a response from options: 'much more than usual', 'rather more than usual', 'less than usual', and 'much less than usual'. The Likert scoring method provided a summed score for the 12 items ranging from 0 (least symptoms) to 36 (most symptoms). ${ }^{26}$

\section{Temporal work patterns}

We summed the number of hours participants on average worked per week, worked as overtime in a normal week, and worked in any second jobs. Mindful of the lack of consensus in categorising work hours, we chose to adhere to a definition and reference group used in epidemiology studies in the UK: $35-40$ hours 
(standard full-time; reference category), 41-54hours (long hours), and 55 hours and over (extra-long hours). ${ }^{23}$ To this we added an additional category to account for part-time workers: fewer than 35 hours per week.

Participants were also asked if they ever worked weekends, with three response options: no weekend working (reference category); some weekends; most/all weekends.

\section{Covariates}

As demographic, socioeconomic and lifestyle factors are determinants of mental health and also associated with work patterns, ${ }^{27}$ we adjusted for: age and age-squared (with the quadratic term added because existing evidence suggests that the trajectory of depressive symptoms in adulthood is u-shaped) ${ }^{28}$ marital status (single, married/cohabiting, separated/divorced/widowed); children in the household (no children, youngest child aged 0-4 years, 5-9 years, 10-15 years); educational attainment (degree or higher, A level or equivalent, GCSE or equivalent, other qualification, no qualifications); equivalised gross monthly household income, created from two variables (gross household income and the modified OECD equivalence scale to adjust for the relative cost of living of households of different compositions). ${ }^{29}$ We adjusted for health behaviours: smoking status (never-smoker, ex-smoker, and current smoker); and a binary indicator of doctor-diagnosed chronic illness (congestive heart failure, coronary heart disease, angina, heart attack or myocardial infarction, stroke, cancer or malignancy, or diabetes).

To account for potential impacts on health from work characteristics such as employment relations, we used the three-category version of the National Statistics Socio-economic Classification (NS-SEC). ${ }^{30}$ This classified people according to their main job: managerial/professional, intermediate, and routine. As the psychosocial work environment is deemed an important link between work and depression ${ }^{21}$ we included the following potential mediators in our models: satisfaction with income (satisfied, neutral satisfaction, dissatisfied); physicality of the job (not at all physical, not very physical, fairly physical, very physical); job satisfaction (satisfied, neutral satisfaction, dissatisfied); and work autonomy (five items measuring autonomy over job task, work pace, work manner, task order, and work hours were summed and reverse coded to give a score of 1 to 20 with higher scores representing greater autonomy).

\section{Analysis}

To account for missing data on exposures and covariates, we applied multiple imputation by chained equations and imputed 33 datasets for each sample of men and women. The imputation model included all analysis variables, and the regressions excluded imputed outcomes (GHQ-12). ${ }^{31}$ Complete case results (shown in the online supplementary tables) were substantially in line with imputed results.

Further to a formal test for gender interactions (not shown, available on request) gender-stratified associations between the atypical work patterns and depressive symptoms were tested using ordinary least squares (OLS) regression models. The first model adjusted for age. The second added more demographic, socioeconomic and health factors. Finally, psychosocial work factors were included. Accounting for the complex design of the UKHLS, study design weights are provided with the data so that the results can be generalised to the UK population. These account for unequal selection probabilities, potential sampling error, non-response of eligible participants, the survey instrument, and the type of observational study. Our analyses used survey commands in Stata V.14. We applied the recommended weight reflecting the cross-sectional study and use of data from the wave 2 self-completion module.

\section{RESULTS}

The distribution of analysis variables in the gender-stratified sample of workers are shown in table 1. In all samples the majority were married, aged 35 years and older, had no children, had no diagnosed chronic illness, and had income satisfaction and job satisfaction.

\section{Weekly work hours}

Men tended to work longer hours than women: almost half the men worked longer than the standard 35-40 hours/week compared with less than a quarter of the women, and nearly half of women worked part-time ( $<35$ hours/week) compared with $15 \%$ of men. Education, income and occupational classification were positively associated with work hours for men and women; however, whereas having children and being married were negatively associated with long work hours for women, the opposite was found for men. Generally, part-time workers were the most likely to be in routine jobs and have the least work autonomy, whereas those working extra-long hours ( $\geq 55$ hours/week) had the highest household incomes and greatest work autonomy.

\section{Weekend working}

More men than women worked weekends: over two-thirds of men and half of the women worked at weekends. Of these, the majority worked some rather than most/all weekends. In contrast to our findings above, although married men worked the longest hours they were not more likely to work weekends; and generally, among both men and women, age, education, income and occupational classification were negatively associated with weekend work. There were also differences relating to the frequency of weekend working, with those working most/ all weekends more likely to be in routine jobs, in the least physically active jobs, with the most income dissatisfaction, the least job satisfaction, and the lowest work autonomy. Both men and women working some weekends had more work autonomy than those in either of the other categories.

\section{Depressive symptoms}

Table 2 presents unadjusted mean depressive symptoms for the temporal work patterns, covariates, and work conditions. Compared with the reference categories (35-40 hours/week; no weekends), there was no difference in the number of depressive symptoms for men working fewer or longer hours or any weekends, whereas women working $\geq 55$ hours/week and those working most/all weekends had significantly more symptoms.

Generally, in both genders, relative to the reference categories, the number of symptoms were higher for older workers, smokers, and participants with the lowest household incomes, chronic illness, job and income dissatisfaction, very physical jobs and the lowest work autonomy. In terms of gender differences, men who were single, in routine occupations, and had GCSE or no qualifications had fewer depressive symptoms; whereas women who were separated/divorced/widowed, had older children, and had GCSE and 'other qualifications' had the highest number of symptoms.

\section{Temporal work patterns and depressive symptoms Weekly work hours}

As table 3 shows, in all models, women working extra-long hours ( $\geq 55$ hours/week) had more depressive symptoms relative to women working standard hours (35-40 hours/week). Men working part-time ( $<35$ hours/week) had significantly more 


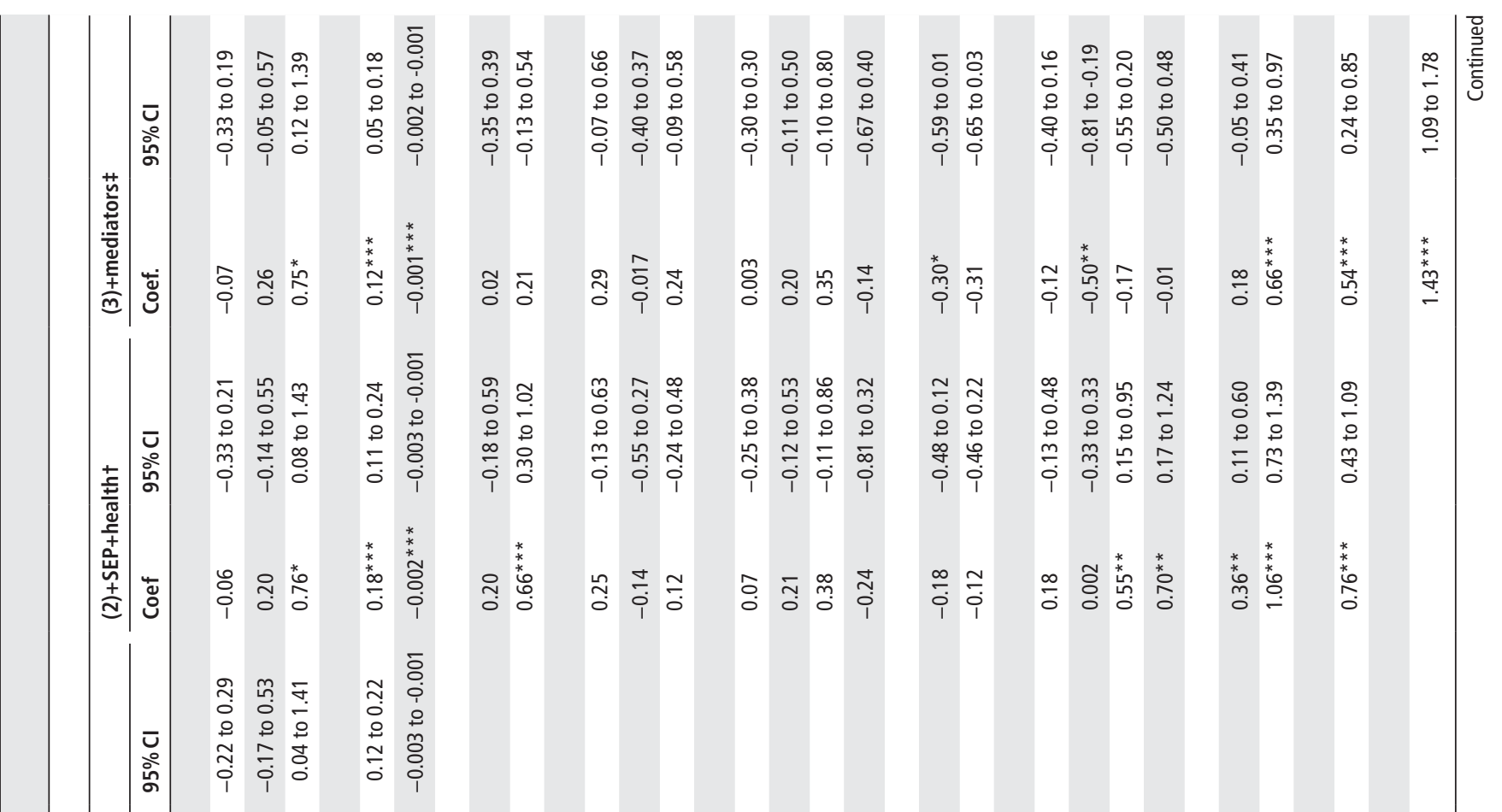

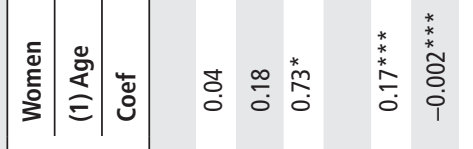

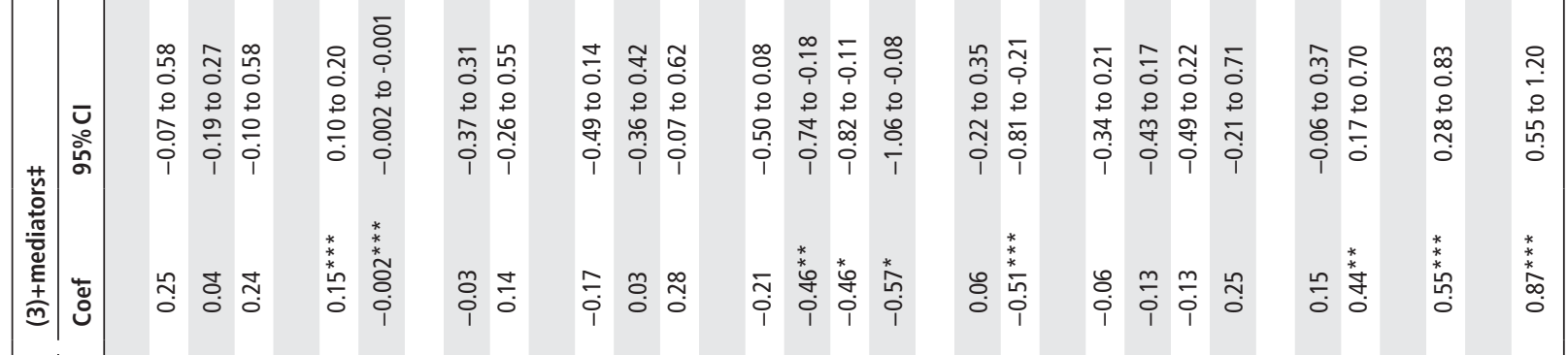

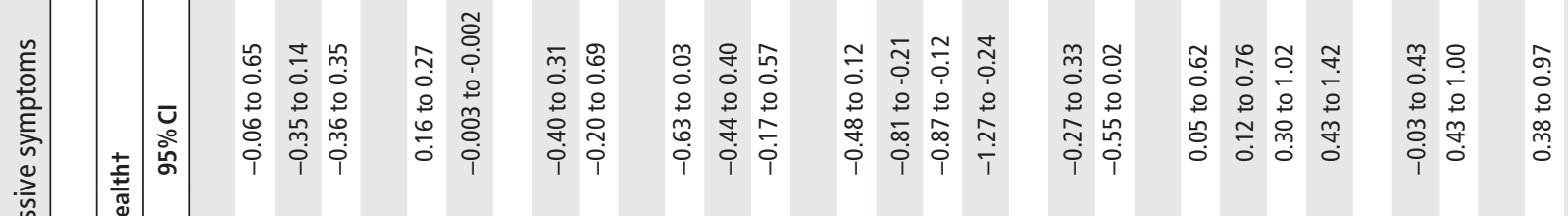

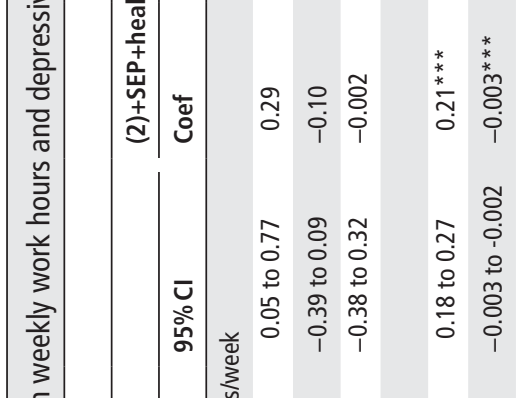

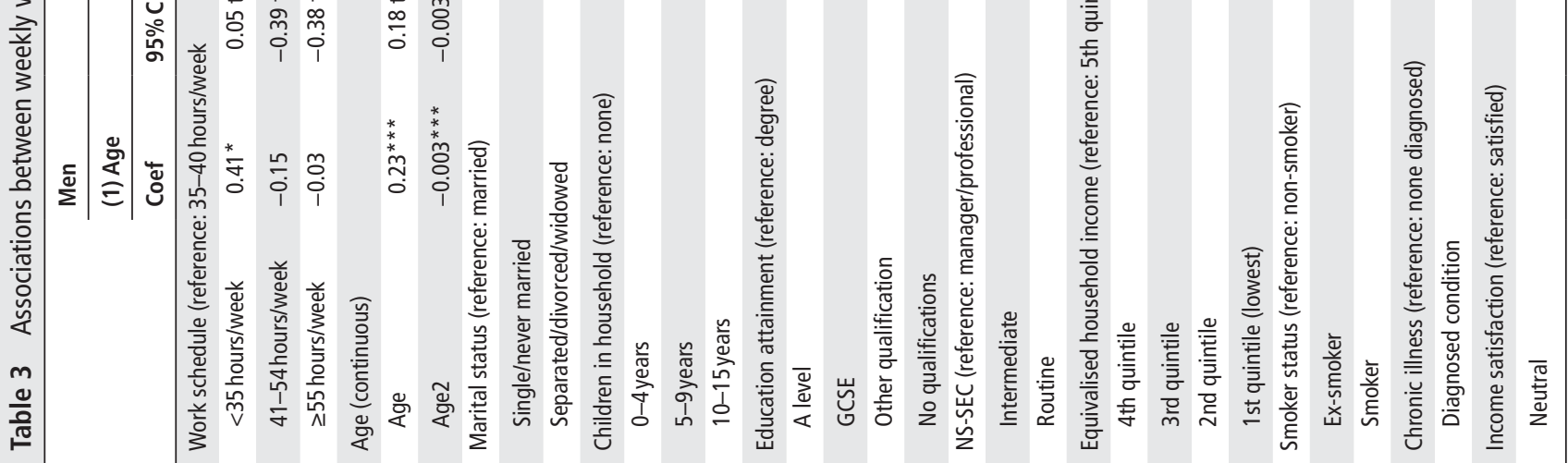


symptoms than men working standard hours, but this association was attenuated by the inclusion of education, income and chronic illness. In all models, relative to working standard hours, there was no difference in symptoms for women working parttime ( $<35$ hours/week) or long hours (41-54hours/week), or among men working long hours (41-54 hours/week) or extralong hours ( $\geq 55$ hours/week).

\section{Weekend working}

As shown in table 4, compared with no weekend working, women working most/all weekends had significantly more depressive symptoms in the minimally adjusted model, and this was only slightly attenuated on further adjustment, whereas there was no association with some weekends, even after adjustment. Among men, only after accounting for work conditions was weekend working (most/all and some weekends) associated with significantly more depressive symptoms.

\section{DISCUSSION}

\section{Main findings}

Atypical temporal work patterns were associated with small but statistically significant elevations in depressive symptoms in a nationally representative sample of working people in the UK, which was unrestricted by occupations, employer, age or sex, and which took account of psychosocial work factors.

Our results suggest that depressive symptoms were slightly higher among weekend workers compared with non-weekend workers. Furthermore, among women, there was a suggestion of a dose-response-type pattern, while among men, psychosocial work conditions appeared to play a role in the linkage between weekend working and depressive symptoms. Men who worked weekends had higher job satisfaction than those who did not work weekends, so higher levels of depressive symptoms emerged once this was taken into account. This study extends the limited amount of published research on weekend working, which though not gender-stratified, had shown higher emotional exhaustion and job stress among weekend workers, ${ }^{11,12}$ and in an occupation specific sample, had found higher psychological strain linked to the frequency of weekend working. ${ }^{13}$ In contrast, a national cross-sectional study of employees in France, which had disaggregated by gender, found no association between weekend working and depressive symptoms. ${ }^{14}$ However, it restricted its definition of weekend workers to those working 'at least one Sunday or Saturday every week', resulting in a sample of $17 \%$ women and $19 \%$ men with this work pattern. Our analyses differentiated between 'most/all' and 'some' weekend working, resulting in a less heterogeneous reference group of non-weekend workers, and a greater proportion overall of weekend workers (67\% of men and 51\% women) in our sample.

Our results also suggest that among women, but not men, working extra-long hours ( $\geq 55$ hours/week) is linked to more depressive symptoms than working standard full-time hours, which corresponds with previous findings of stronger associations between long work hours and depressive disorders for women than men. ${ }^{17} 23$ We also found elevated symptoms of depression among men working the fewest hours ( $<35$ hours/ week), but this effect was explained by socioeconomic and physical health disadvantages among this group. Due to the cross-sectional nature of our study we cannot confirm that men were selected into part-time work because of their health; however, it is noteworthy that previous research found that individuals with health problems were more likely to work part-time rather than full-time. $^{32}$ 


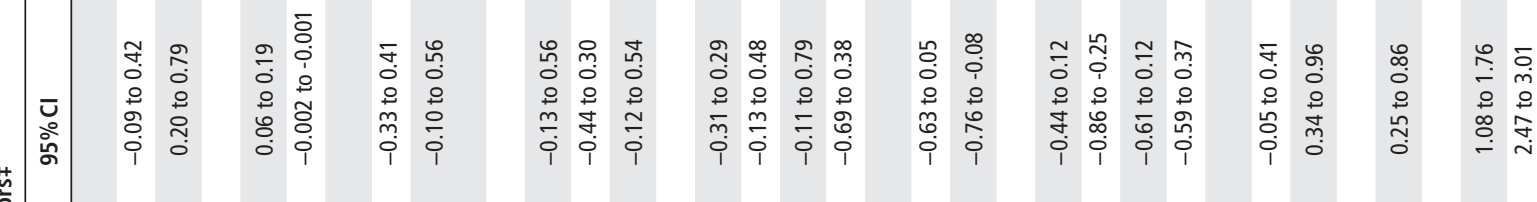

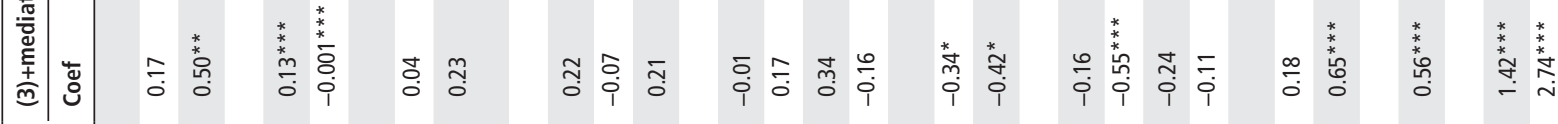

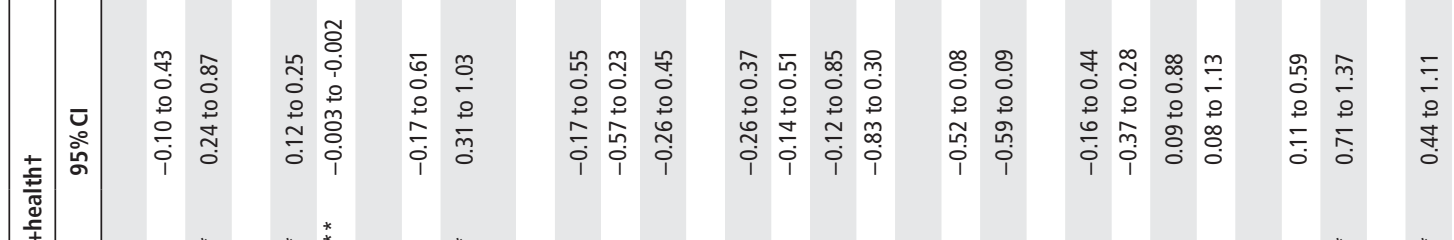

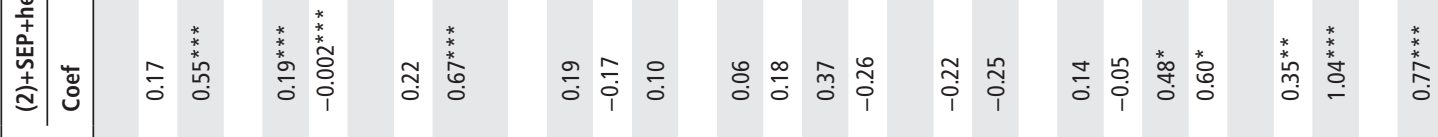

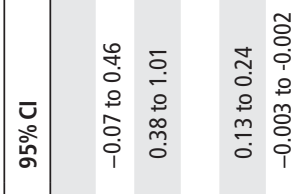

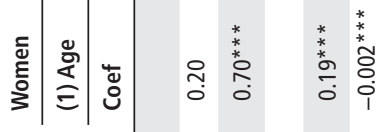

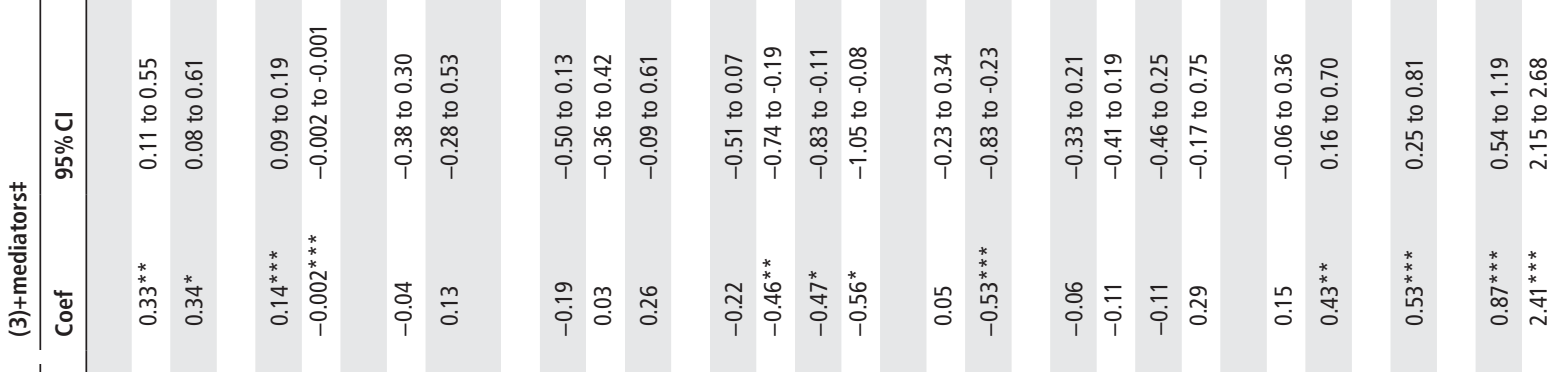

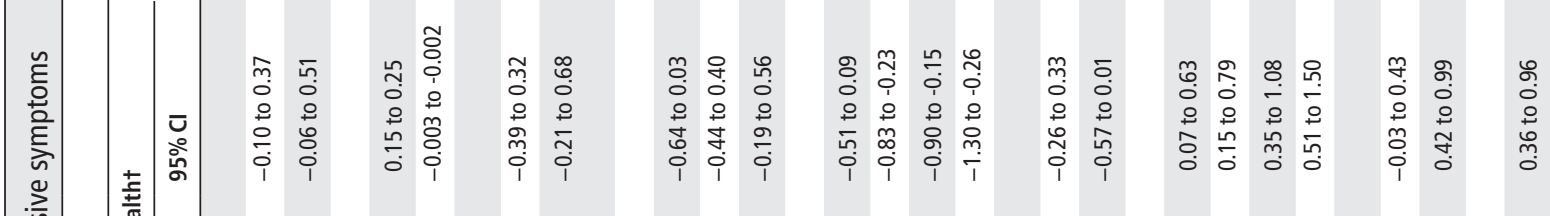

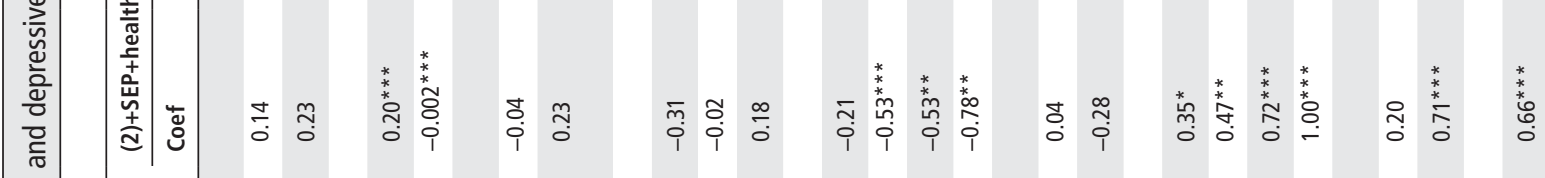

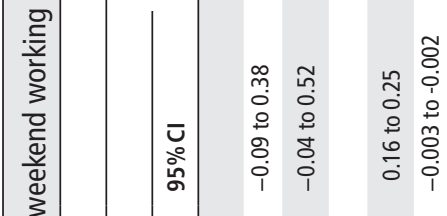

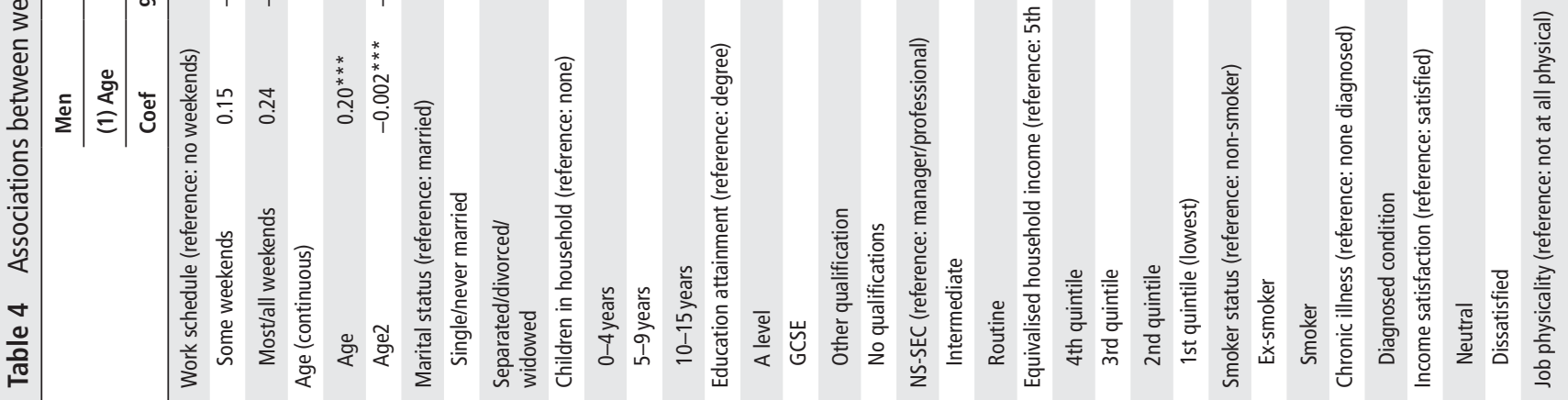




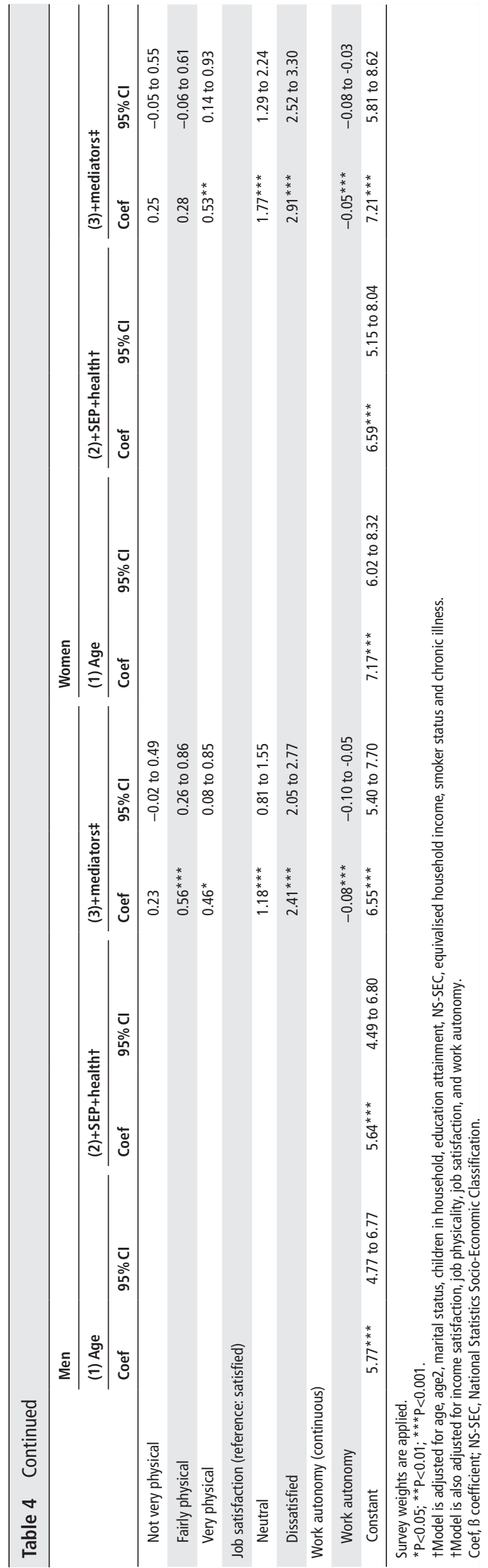

\section{Mechanisms and implications}

Potential pressures arising from working against social and labourforce norms might explain why there were elevated depressive symptoms among those women working extra-long hours and most/all weekends. Consistent with this suggestion are reports that it is usual in UK society for men to work longer hours ${ }^{33}$ and weekends $^{34}$; indeed in our sample, only $4 \%$ of women worked extra-long hours compared with three times as many men, and about 33\% more men than women worked at weekends. Another explanation for the differences we found for men and women might relate to the gendered nature of some work: women have been found to work longer hours in male-dominated occupations ${ }^{35}$; and women working weekends tend to be concentrated in low-paid service sector jobs. ${ }^{36}$ Such jobs, when combined with frequent or complex interactions with the public or clients, have been linked to higher levels of depression. ${ }^{37}$ Our finding of more depressive symptoms among women working extra-long hours might also be explained by the potential double-burden experienced by women when their long hours in paid work are added on to their time in domestic labour. Previous studies have found that once unpaid housework and caring is accounted for, women work longer than men on average, ${ }^{38}$ and that this has been linked to poorer physical health. ${ }^{39}$ An investigation into the combined effects of domestic labour and work patterns was beyond the scope of this paper, but this could be an interesting avenue for future research.

\section{Strengths and limitations}

Although previous studies are informative about temporal work patterns for specific groups of workers or their physical health, our study is unique in focusing on a large, nationally representative, heterogeneous sample of workers of all ages $(16+)$ with results that are generalisable to the UK. This sample enabled us to analyse data on women as well as men, reflecting the participation of both genders in the workforce and their different experiences of paid work.

Depressive symptoms were measured using the GHQ-12 scale, a validated standard measure of common mental health, but due to the cross-sectional design of our study, we cannot rule out the possibility of pre-existing symptoms. However, we consider it unlikely that depressed workers would select into long hours and weekend schedules. Indeed, longitudinal studies found that workers who

\section{What is already known on this topic}

- The global and gig economies are driving the need for people to work atypical temporal schedules, like weekends and long hours. Some of these schedules have been associated with physical health disorders but less is known about their relationships with mental health.

- Existing studies focus mainly on men and specific occupations, but rarely examine the effects of weekend working or account for psychosocial working conditions.

\section{What this study adds}

- Results from this population-based study show gender differences in the associations between atypical temporal work schedules and depressive symptoms, with women who work extra-long hours and most/all weekends experiencing the poorest mental health.

- Men working weekends also experience poorer mental health when their psychosocial conditions are poor. 
experienced deterioration in their mental health adapted to it by reducing their work hours and changing their work patterns and jobs $^{40}$; also, long work hours were a causal factor for depressive symptoms among civil servants. ${ }^{23} 41$

\section{CONCLUSION}

Our study shows a link between atypical temporal work patterns and depressive symptoms, but there are gender differences in these associations. The poorest mental health is experienced by women working extra-long hours and most/all weekends, and by men with poor psychosocial work conditions working at weekends. Our findings should encourage employers and policymakers to consider interventions aimed at reducing women's burdens without restricting their full participation in the workforce, and at improving psychosocial work conditions.

\section{Correction notice This article has been corrected since it first published.}

Contributors This study was conceived of and planned by all authors. GW undertook the data analysis, with statistical advice and contributions from all authors on the results and interpretation. GW led on writing the manuscript with contribution and editing from all authors, and approval from all on the final version. GW is the guarantor for the study.

Funding GW was self-funded in this study. AZ is supported by a grant from the Economic and Social Research Council [ES/R003114/1]. AM and EW were supported by the Economic and Social Research Council International Centre for Lifecourse Studies in Society and Health (ICLS) [grant number ES/J019119/1]. LAC is supported by the Medical Research Council, UK

Competing interests None declared.

Patient consent for publication Not required.

Ethics approval Ethical approval was not required for this secondary data analysis. The Understanding Society, UKHLS study had been approved by the University of Essex ethics committee.

Provenance and peer review Not commissioned; externally peer reviewed.

Data sharing statement The UKHLS dataset is available under End User Licence from the UK Data Archive (http://www.ukdataservice.ac.uk).

Open access This is an open access article distributed in accordance with the Creative Commons Attribution 4.0 Unported (CC BY 4.0) license, which permits others to copy, redistribute, remix, transform and build upon this work for any purpose, provided the original work is properly cited, a link to the licence is given, and indication of whether changes were made. See: https://creativecommons.org/ licenses/by/4.01.

\section{REFERENCES}

1 Presser HB. Working in a 24/7 economy: challenges for American families. New York: Russell Sage Foundation Publications, 2005.

2 Kondo N, Oh J. Suicide and karoshi (death from overwork) during the recent economic crises in Japan: the impacts, mechanisms and political responses. J Epidemiol Community Health 2010;64:649-50.

3 Shan HP, Yang XH, Zhan XL, et al. Overwork is a silent killer of Chinese doctors: a review of Karoshi in China 2013-2015. Public Health 2017;147:98-100.

4 Parent-Thirlon A, Biletta I, Vargas 0, et al. Sixth European Working Conditions Survey overview report. Luxembourg: Eurofound, 2016.

5 Cabrita J, Boehmer S, Galla da Bino C. Working time developments in the 21st century: Work duration and its regulation in the EU | Eurofound. 2016./publications/ report/2016/industrial-relations-law-and-regulation/working-time-developments-inthe-21st-century-work-duration-and-its-regulation-in-the-eu. (Accessed 2 Dec 2016).

6 Health and Safety Executive. Statistics - Working days lost. http://www.hse.gov.uk/ statistics/dayslost.htm (Accessed 2 Dec 2016).

7 Vogel M, Braungardt T, Meyer W, et al. The effects of shift work on physical and mental health. J Neural Transm 2012;119:1121-32.

8 Wirtz A, Nachreiner F, Rolfes K. Working on Sundays-effects on safety, health, and work-life balance. Chronobiol Int 2011;28:361-70.

9 Hosking A, Western M. The effects of non-standard employment on work-family conflict. Journal of Sociology 2008;44:5-27.

10 Fenwick R, Tausig M. Scheduling stress: family and health outcomes of shift work and schedule control. Am Behav Sci 2001:44:1179-98.

11 Jamal M. Burnout, stress and health of employees on non-standard work schedules: a study of Canadian workers. Stress Health 2004;20:113-9.
12 Davis KD, Goodman WB, Pirretti AE, et al. Nonstandard work schedules, perceived family well-being, and daily stressors. J Marriage Fam 2008;70:991-1003.

13 Tucker P, Brown M, Dahlgren A, et al. The impact of junior doctors' worktime arrangements on their fatigue and well-being. Scand I Work Environ Health 2010;36:458-65

14 Niedhammer I, Lesuffleur T, Algava E, et al. Classic and emergent psychosocial work factors and mental health. Occup Med 2015;65:126-34.

15 Virtanen M, Kivimäki M. Saved by the bell: does working too much increase the likelihood of depression? Expert Rev Neurother 2012;12:497-9.

16 Bannai A, Tamakoshi A. The association between long working hours and health: a systematic review of epidemiological evidence. Scand J Work Environ Health 2014;40:5-18.

17 Watanabe K, Imamura K, Kawakami N. Working hours and the onset of depressive disorder: a systematic review and meta-analysis. Occup Environ Med 2016;73:0em ed-2016-103845.

18 . Gender and Work - Sociology - Oxford Bibliographies. http://www. oxfordbibliographies.com/view/document/obo-9780199756384/obo9780199756384-0127.xml (Accessed 15 Jan 2018).

19 Rivera-Torres P, Araque-Padilla RA, Montero-Simó MJ. Job stress across gender: the importance of emotional and intellectual demands and social support in women. Int $J$ Environ Res Public Health 2013;10:375-89.

20 Artazcoz L, Borrell C, Cortès I, et al. Occupational epidemiology and work related inequalities in health: a gender perspective for two complementary approaches to work and health research. J Epidemiol Community Health 2007;61:ii39-45.

21 Bonde JP. Psychosocial factors at work and risk of depression: a systematic review of the epidemiological evidence. Occup Environ Med 2008;65:438-45.

22 Conway SH, Pompeii LA, Gimeno Ruiz de Porras D, et al. The identification of a threshold of long work hours for predicting elevated risks of adverse health outcomes. Am J Epidemiol 2017;186:173-83.

23 Virtanen $M$, Ferrie JE, Singh-Manoux A, et al. Long working hours and symptoms of anxiety and depression: a 5-year follow-up of the Whitehall II study. Psychol Med 2011:41:2485-94.

24 Marmot M, Brunner E. Cohort Profile: the Whitehall II study. Int J Epidemio/ 2005;34:251-6.

25 Böhnke JR, Croudace TJ. Calibrating well-being, quality of life and common mental disorder items: psychometric epidemiology in public mental health research. $\mathrm{Br} J$ Psychiatry 2016;209:162-8.

26 Cox B, Blaxter M, Buckle AJ, et al. The health and lifestyle survey. London: Health Promotion Research Trust, 1987.

27 Bara AC, Arber S. Working shifts and mental health-findings from the British Household Panel Survey (1995-2005). Scand J Work Environ Health 2009;35:361-7.

28 Sutin AR, Terracciano A, Milaneschi Y, et al. The trajectory of depressive symptoms across the adult life span. JAMA Psychiatry 2013;70:803-11.

29 Chanfreau J, Burchardt T. Equivalisation scales: rationales uses and assumptions. 2008 www.gov.scot/resource/doc/933/0079961.pdf

30 Chandola T, Jenkinson C. The new UK national statistics socio-economic classification (NS-SEC); investigating social class differences in self-reported health status. J Public Health 2000;22:182-90.

31 White IR, Royston P, Wood AM. Multiple imputation using chained equations: issues and guidance for practice. Stat Med 2011;30:377-99.

32 Gannon B, Roberts J. Part-time work and health among older workers in Ireland and Britain. App/ Econ 2011;43:4749-57.

33 Davaki K. Differences in men's and women's work, care and leisure time. European Union 2016. http://www.europarl.europa.eu/RegData/etudes/STUD/2016/556933/ IPOL_STU(2016)556933_EN.pdf (Accessed 22 Nov 2017).

34 Presser HB, Gornick JC, Parashar S. Gender and nonstandard work hours in 12 European countries. Mon Labor Rev 2008;131:83-103.

35 Hegewisch A, Hartmann H. Occupational segregation and the gender wage gap: a job half done. 2014 https://iwpr.org/wp-content/uploads/wpallimport/files/iwpr-export/ publications/C419.pdf (accessed 2 Jul 2018).

36 Presser HB, Gornick JC. The female share of weekend employment: a study of 16 countries. Mon Labor Rev MLR Wash 2005;128:41-53.

37 Wulsin L, Alterman T, Timothy Bushnell P, et al. Prevalence rates for depression by industry: a claims database analysis. Soc Psychiatry Psychiatr Epidemiol 2014;49:1805-21.

38 ILO. Women at work: trends 2016 international labour organization. 2016 http:// www.ilo.org/wcmsp5/groups/public/-dgreports/-dcomm/-publ/documents/publication/ wcms 457317.pdf (Accessed 1 Mar 2018).

39 Thomas CL, Laguda E, Olufemi-Ayoola F, et al. Linking job work hours to women's physical health: the role of perceived unfairness and household work hours. Sex Roles 2018;13.

40 De Raeve L, Kant I, Jansen NW, et al. Changes in mental health as a predictor of changes in working time arrangements and occupational mobility: results from a prospective cohort study. J Psychosom Res 2009;66:137-45.

41 Virtanen M, Stansfeld SA, Fuhrer R, et al. Overtime work as a predictor of major depressive episode: a 5 -year follow-up of the Whitehall II study. PLoS One 2012:7:e30719. 